\title{
Conditional Style Rotation Model on Enhanced Value and Growth Portfolios: The European Experience
}

\author{
Ron Bird $^{\mathrm{a} \dagger}$ and Lorenzo Casavecchia ${ }^{\mathrm{a}}$ \\ The Paul Woolley Centre @ UTS \\ Working Paper Series 2 \\ May 2008
}

\author{
${ }^{\mathrm{a}}$ The Paul Woolley Centre for Capital Market Dysfunctionality, University of \\ Technology, Sydney, \\ Cnr Quay Street and Ultimo Road, PO Box 123, 2007, Sydney, Australia
}

\begin{abstract}
Academic and professional attention has been devoted in the past to the analysis of the potential value-enhancement generated by strategies based on macroeconomic models and applied to portfolios or indexes of style classes. In this paper, we analyse the extent of the excess returns that can be potentially generated by rotating a portfolio between value and growth stocks in the European markets. We extend the results obtained by Bird and Casavecchia (Bird, R. and Casavecchia. L. (2007) Sentiment and financial health indicators for value and growth stocks: the European experience, European Journal of Finance, 13, pp. 769-793) when applying market sentiment and financial health indicators to stocks and document the extent to which macroeconomic factors convey information that is not already impounded in these indicators. We find that a strategy to rotate between portfolios, constructed on either single valuation metrics or their enhancement by market sentiment and a company's financial strength, is typically consistent, monotonic, and in the expected direction. This highlights the proposition that the macroeconomic factors capture a cross-sectional variation that is not typically impounded in unconditional regression models on value and growth portfolios.
\end{abstract}

KEY WORDS: Style rotation, financial health, market sentiment, asset pricing anomalies.

JEL: G11, G15, F47.

\footnotetext{
$\dagger$ Correspondence Address: School of Finance and Economics, University of Technology, Sydney, PO Box 123, Broadway, NSW, Australia, 2007, Tel.: +61 (2) 9514 7716, Fax: +61 (2) 9514 7722, Email: ron.bird@uts.edu.au
} 


\section{Introduction}

There is widespread empirical evidence that the relative performance of value and growth portfolios and so the magnitude of the value premium (the excess performance of value portfolios over growth portfolios), is related to the current state of the economy. This evidence has lead many writers to examine the extent to which macroeconomic variables can be used, in some instances in concert with other variables, to forecast those periods during which it would be preferable to hold the value portfolio and those when it would be preferable to hold the growth portfolio (Case and Cusimano, 1995; Chan et al., 2000; Oertmann, 1999). In this paper we aim to integrate a style rotation model into the contextual fundamental framework developed by Bird and Casavecchia (2007), in order to capture common dynamic patterns as represented by a standard set of economy-wide instruments.

Bird and Casavecchia (2007) built an enhancement for value and growth stocks based upon both the market sentiment towards a stock and its financial health (hereafter, FH) and so constructed four portfolios consisting of "good" (strong both in market sentiment and FH) and "bad" (weak both in market sentiment and FH) value and growth stocks. After first replicating their results ${ }^{\mathrm{i}}$, our contribution to the existing literature is to develop a macroeconomic model that will allow us to choose between portfolios consisting of "good" value stock and "good" growth stocks. Therefore, we will implement a style-based timing strategy using macroeconomic factors that have been widely cited in the literature as having a predictable influence on stocks returns (see Keim \& Stambaugh, 1986; Campbell, 1987; Campbell \& Shiller, 1988; Ferson \& Harvey, 1991; 1999). The intertemporal performances of growth stocks relative to value stocks are directly dependent on the changes in the intertemporal sensitivities of each of these styles. For instance, while growth stocks, on average, underperform value stocks, they evidence an ability to outperform in periods when the business cycle is strong. Our main result is that a style rotation strategy, determined on the basis of business cycle indicators, is able to significantly improve the performance of either a long-only or a long/short strategy based on value and growth portfolios. However, the extent of any added performance attributable to style rotation erodes when enhancement are applied to these value and growth portfolios by introducing first a market sentiment and then a FH indicator.

The remainder of this study is organised as follows. In the next section we will explore the macroeconomic instrumental variables used to time the switches between the different styles. In section 3, we will give special emphasis to the methodology employed in the analysis. Section 4 reports the main findings from applying the model in terms of both its ability to forecast which of value and growth styles will outperform, and how this can be used to further augment value and growth investment strategies already enhanced by the use of market sentiment and FH indicators. The last section provides the conclusions.

\section{Data}

\subsection{Financial Variables}

The initial sample consists of almost 8000 firms from fifteen European countries ${ }^{\text {ii }}$. The analysis was conducted over almost fifteen years, from 1990 to 2004 . We obtained the 
accounting data from Compustat Global Vantage, compiled by Standard and Poor's Inc.; stock returns and certain other price-related variables from the proprietary database of GMO London; the macroeconomic data are from Datastream. Consistent with previous studies, we excluded from our sample all stocks belonging to the financial sector, those with a negative book value, and those with a price of less than one pound (or the equivalent in other currencies) ${ }^{\text {iii. }}$. The result is a sample constituted by an average of approximately 4,231 stocks in each month and a total of 782,739 observations. The study was conducted by using a common currency (namely, the UK pound sterling) ${ }^{\mathrm{iv}}$.

\subsection{Macroeconomic Instruments}

We need to develop different proxies for the fluctuations in the business cycle in order to test for any relationship between the value premium and the current economic phase. Our choice of macroeconomic variables is influenced by the findings of numerous studies that have been previously investigating the link between security prices and macroeconomic information. The factors that have been chosen for inclusion are:

- UI: indicating the monthly unexpected inflation. The data for the European Consumer Price Index (CPI) is provided by Datastream Thompson Financial;

- Baa-Aaa: the average monthly yield-to-maturity of corporate bonds rated Baa less the Aaa average corporate bond yield, provided by Moody's Investor Services (Keim \& Stambaugh, 1986; Fama \& French, 1989);

- Euro DY: the monthly dividend yield (D/P) on European markets exFinancials, provided by Datastream (see Fama \& French, 1988);

- YTM: the monthly change in the spread between the yields of the 10-year Government Bond and that of the 3-month Treasury Bill, provided by Datastream;

- Real T.B.: the 3-month Treasury Bills returns less the monthly rate of inflation, provided by Datastream Thompson Financial (Campbell, 1987; Ferson \& Harvey, 1991).

In relation to the calculation of the unanticipated inflation (UI), we followed the procedure proposed by Fama and Gibbons (1984) and the back-forecasting method of Box and Jenkins $(1976)^{\mathrm{v}}$. The UI is the residual of a moving average model of the change from month $t-1$ to month $t$ in the natural log of the European CPI (designated as $I_{t}$ ). The analysis of the autocorrelation coefficients of the monthly change in the inflation rate, significant in the first period and noisy thereafter, suggests, as in the case of the US sample, a first-order moving average method of the inflation, where:

$$
I_{t}-I_{t-1}=\hat{\alpha}_{t}-\vartheta \hat{\alpha}_{t-1}
$$

The estimation of the MA model returned the following values for the moving average parameter $\vartheta$ :

$$
I_{t}-I_{t-1}=\hat{\alpha}_{t}-05588 \hat{\alpha}_{t-1} \quad s(\vartheta)=0.0029
$$


On the US sample, Fama and Gibbons obtained a value of the parameter $\vartheta$ equal to -0.8027 and argued that only $20 \%$ of the unexpected inflation is impounded in the expected inflation rate in each month. In our European sample, instead, this percentage raises to almost $44 \%$.

In addition to the macroeconomic variables in our model, we also included as an explanatory variable the value premium over the previous 12 months $\left(\Delta v_{t}\right)$. The reason for its inclusion is that the monthly change in the difference between value and growth portfolios is autocorrelated. Hence, it might convey information not impounded in the economic variables yet, constituting a relevant factor in the attempt to signal the switches between the two styles.

In Table 1, we document the main descriptive statistics (upper table) and the correlation (lower table) among the macroeconomic variables. The values of the statistics and correlation (obtained with a bootstrap over 10,000 draws) are in line with the results obtained in previous studies.

\section{The methodology}

We calculated the value premium as the difference between the return of a value portfolio (in the top $1 / 4$ of the sales-to-price rankings) and that of a growth portfolio (in the bottom $1 / 4$ of the sales-to-price rankings). In order to quantify the time-varying sensitivities of the value premium to the different macroeconomic instrumental variables we decided to adopt a simple weighted least square technique, instead of the more common dichotomous regressions (see Arshanapalli et al., 2007), for the following reasons:

1. No loss of information: reducing the time series of the dependent variable represented by the value premium to a dichotomous realization would generate a relevant loss of information related to large swings towards one or the other style, as determined by market sentiment ${ }^{\mathrm{vi}}$;

2. Weighting scheme: it permits us to better weight the level of autocorrelation in the value premium and the decreasing influence of the independent macroeconomic variables over the in-sample estimation period (Biørn, 2001). The weighted least square (hereafter WLS) is also appropriate to deal with the heteroskedasticity affecting the variables employed in our analysis ${ }^{\text {vii }}$, when, as in our case, the scale of the weight series is not relevant in the estimation procedure. Moreover, the WLS estimations can be accompanied by the use of the White (1980) and Newey-West (1987) covariance matrix estimates. We will refer to these estimates in order to control for the presence of heteroskedasticity and autocorrelation.

The WLS regression can be expressed by the following equation:

$$
E_{t}\left(v_{t+1}\right)=\alpha_{t}+\varphi_{t} \Delta v_{t}+\sum_{j=1}^{n} \beta_{j, t}^{\prime} Z_{j, t}
$$

where $v_{t+1}$ constitutes the value premium in the next period, $\Delta v_{t}$ is the change in the value premium in period $t$, and $Z_{j, t}$ represents the value of our lagged $j^{\text {th }}$ macroeconomic instrumental variable at time $t$. 
In the basic ordinary least-squares fitting scenario, when we minimize the error term $\varepsilon_{t}$, we assume that each of the $N$ equations is equally important. In the real world, not all data are equally reliable or in the case of financial and macroeconomic data, weighting them equally, over the entire in-sample period, would imply a constant and invariant effect of the independent variables on the dependent variable (in our case the value premium). In estimating the dependent variable, we would like to give more weight to the most recent observations without throwing away the old observations because they still may contain some useful information about the cross-section of the returns. For this reason, we decided to scale the observations with an exponential time-weighting scheme, where the observation are exponentially weighted in the in-sample period ${ }^{\text {viii }}$. Because we adopted a 36-month in-sample estimation period, the model attributes exponentially a lower weight $\left(w g t_{i}\right)$ to the more distant observations. In this case, the adjustment to the regression model is:

$$
\varepsilon=\left\{\sum_{i=1}^{N}\left(a_{i 1} x_{1}+a_{i 2} x_{2}+\ldots-b_{i}\right)^{2}\right\} w g t_{i}
$$

Moreover, we also analyse the potentials of a style rotation strategy by running a bootstrap with 10,000 draws in order to emphasize not only the profitability of a style timing but also the natural hurdles that these strategies need to overcome to be remunerative, with this being strictly dependent also on the holding period adopted in the portfolio construction.

In table 2 we report the regression coefficients, the t-statistics and the MSE, as a general check of the fit of the model for the multivariate regression where the dependent variable (next-period value premium) is regressed against all the independent variables listed in the table ${ }^{\mathrm{ix}}$. In the same table we also document the coefficients of the univariate regressions.

The 36-month window of the in-sample estimation period attributes higher relevance to the more recent observations. The multivariate WLS-exponential findings evidence a result similar to what is documented in the literature. Firstly, the positive and significant beta of the previous-month value premium is generated by the autocorrelation function ${ }^{\mathrm{x}}$ and it helps in predicting the direction of the value-growth spread. Second, the positive coefficient of the YTM suggests that in periods of small YTM (expansionary periods), stocks with growing characteristics should show higher returns because of better market expectations, or simply because a decrease in the long-term rates relative to the shortterm rates increases future cash flows or reduces the discount factors at which these cash flows are capitalized. The results for the univariate estimates confirm the signs and significance of the multivariate analysis. In Figure 1, instead, we illustrate the (WLS) time-varying sensitivities of the value premium to the instrumental variables. We also highlighted the two periods when the sensitivities registered a drastic inversion: MarchSeptember 2001 (period 1) and January-December 2003 (period 2), the latter officially classified by the NBER Business Cycle Dating Committee as a recessionary period. The most intriguing evidence comes from the beta of the dependent variable $\left(\mathrm{V}_{t+1}\right)$ to the YTM, considered its sharp increase (from almost zero to 3.5) in period 1, when the YTM in most of the European markets widens, and its contraction (from 5.7 to 1.8) in period 2, when the YTM flattens. A rising (flattening) yield curve is a signal of worse (improved) market expectations, which benefits the returns of value (growth) stocks.

In period 1 (2), most of the markets in Europe experienced a concomitant: (i) gradual contraction (expansion) in the credit risk, (ii) decrease (increase) in the European 
Consumer Confidence Index and Production Price Index, and (iii) sharp rise (fall) in the average dividend yield indicator, which was more the offspring of a price correction rather than a real radical variation in the level of the dividends. Overall, the model(s) seems to be effective in capturing the jumps in the sensitivities of value and growth stocks to the macroeconomic factors used as instrumental variables, suggesting the possibilities of the model providing an effective basis for forecasting the time when best to rotate between value and growth portfolios.

\section{Findings}

In this section, we will document the performance, in term of excess returns, of the various strategies involving rotation between value and growth portfolios. Our economic model aims at forecasting the value premium over the next 12 months to gain insights into whether a simple value or growth portfolio will perform better. We will first proceed to provide evidence on the returns of the style rotation strategy, compared to those of value- and growth-alone portfolios, over different holding periods. We will then quantify the extent of the forecasting ability of the model in the next section. Finally, we will integrate our approach to style rotation with the sentiment and FH indicators to see whether style rotation further enhances the performance of the value and growth portfolios experiencing different phases of sentiment and accounting corrections.

\section{Section 4.1: Market-based Indicators and Macro Rotation}

Each month from January 1993 to May 2004 (out-of-sample period), we rank the stocks according to their sales-to-price ratio and then use these rankings to separate the stocks into quartiles to form four equally weighted portfolios with the top and bottom quartiles constituting the value and growth portfolios, respectively. We also use our macroeconomic regression to forecast which of value and growth will perform best over the next 12 months. We form the "rotation right" ("rotation wrong") portfolio each month by choosing to invest in the value or growth portfolio that our forecasting model predicts will be the best (worst) performing portfolio over the subsequent month. We calculate the average excess return, as measured against our benchmark portfolio (an equally weighted portfolio of all of the stocks in our universe at that point in time) over different holding periods $(3,6,12$, and 24 months) on the following four portfolios: rotation right, value, growth and rotation wrong. In Table 3, we report these excess returns and their associated Newey-West p-values over each of the holding periods considered for each of our portfolios. Value portfolios clearly outperform growth portfolio in each period, with the (annualised) value premium clearly increasing as one lengthens the holding period. Our results confirm that our forecasting model based on macroeconomic variables is able to exploit the sensitivities of the value and growth stocks to changes in economic conditions in order to profit from rotating between them.

Over a 12-month holding period, the right style rotation is able to generate a return slightly in excess of $9.5 \%$, which is $4 \%$ greater than that realised by the value portfolio. Over the same period, the wrong style rotation generates a return less than $-5 \%$, which is $3 \%$ more negative than that realised by growth stocks. It is evident that the style rotation model has enabled us to realise performance well above that which could be achieved if we restricted ourselves to simply investing in the value (or growth) portfolios each month. The added value from style rotation is also strongly evident over 
holding periods of three and six months but would appear to lose its efficacy by the time when the holding period is extended to 24 months. This should come as no surprise as one would expect the style rotation signal to become stale as one extends its application beyond the 12-month forecasting period for the model.

\section{Section 4.2: Forecasting Ability and Timing Leverage: The Accuracy Region}

An important aspect not yet addressed is related to the extent of the forecasting ability of our model. In this regards, we would like to underline the importance for a successful rotation strategy to be able to accurately forecast the periods when value is going to outperform growth and vice versa (forecasting ability) and also the ability to accurately forecast at the right time (timing leverage). For instance, assuming a 70\% forecasting ability (namely, a hit rate of $70 \%$ ), there is a whole range of outcomes consistent with it, reflecting the performance in the periods when the model is correct and those when it is wrong (see Jeffrey, 1984). This wide range of possible outcomes, given a particular forecasting ability, depends on the, sometimes neglected, leverage exerted by the returns in some periods on the final average return of the style rotation approach (hereafter, timing leverage). It is crucial, hence, as a stress test of our findings, to illustrate the efficacy of the model in relation to the two dimensions of forecasting ability and timing leverage. In panel 2.a of Figure 2, we document the result of a bootstrap with 10,000 draws from the vector of the value premium over our out-ofsample period. The elliptic region (hereafter, accuracy region) documents the potential range of returns achievable for each given level of forecasting ability. For instance, an ability to rotate correctly between the two asset classes $70 \%$ of the times obviously would not produce a unique (excess) return, but an entire distribution of returns, according to the timing leverage, which is represented in this subplot by the distance between the best and worst scenarios of the possible rotations between the asset classes. In the best (worst) scenario, the periods when our forecasts are wrong are those when our preferred style only marginally (significantly) underperforms. Each of the points on the two curves of the best and the worst outcomes associated with each level of forecasting accuracy correspond to a distribution of returns. In panel 2.b and 2.c, we illustrate these distributions in the case of the two extreme scenarios of timing leverage. The subplots clearly emphasise the time-dependent marginally decreasing (increasing) improvement a market timer can add to his strategy the better (worse) he is in picking the stocks/portfolios, or, said in another way, it illustrates that a successful rotation strategy could add more or less value depending on the period when the style rotation is implemented.

Continuing on this line, our model returned a forecasting ability of $70 \%$, with ten switches in all from value to growth and vice versa. This figure allows us to position our strategy in the accuracy region of Figure 2.a, and separate the contribution of the forecasting ability (illustrated on the $x$-axis) from that of the timing leverage (represented by the vertical segment connecting the best and the worst scenarios for each level of accuracy). The excess return of $9.53 \%$ for the right rotation, which is almost the half of the best possible return achievable of $23 \%$ for the same forecasting accuracy, seems to suggest that the timing leverage of the model did not contribute much to the return of the portfolio. Overall, these findings are consistent with the conclusions proposed by Jeffrey that a "...timing strategist has tremendous natural odds 
to overcome, and...these odds increase geometrically with the length of time frame and the frequency of the timing interval".

\section{Section 4.3: Market Sentiment and the Business Cycle}

A particular problem associated with the traditional valuation multiples, used to identify value and growth stocks, is that they provide little useful guidance as to when such stocks should be acquired. A major flaw with these multiples, commonly referred to as the "value trap", is that they frequently indicate entry into value stocks too far in advance of any turnaround. In the case of growth stocks, the problem could be the reverse, with the risk of blindly herding the market overvaluation just before the price correction sets in. Asness (1997), and Lee and Swaminathan (2000) emphasised the possibility of using the market sentiment of a stock as a possible solution to the noisy valuation proxy constituted by market-based criteria, because its blending with the latter facilitates the identification of the timing of the price correction process for either value or growth stocks

In order to both quantify the extent of the contribution of the macroeconomic rotation and distinguish it from the dynamic of the momentum life cycle of a stock, we first divide both the value and growth portfolios in accordance with their price momentum, and so form four portfolios:

- value and growth winners (rank in the top one-third by price momentum);

- value and growth losers (rank in the top one-third by price momentum).

We then separately apply style rotation (both right and wrong) to choose between either the value winner and growth winner portfolios or between the value loser and growth loser portfolios. We report in Table $4 \mathrm{a}(4 \mathrm{~b})$ the excess returns over various holding periods for the value winner (loser) and growth winner (loser) portfolios and the associated portfolios implemented with the macroeconomic information (rotation right and rotation wrong).

Starting with panel 4.a, a correct rotation between value and growth stocks timed by their good market sentiment over the previous 6 months would produce a return of $13.83 \%$ over a 12 -month holding period, which is $2 \%$ above the $11.87 \%$ realised by the value winners. Beyond 12 months, the ability of the rotation signals seems to vanish as a result of its in-sample link with a 12-month cycle of the value premium. On the other hand, the rotation wrong portfolio realises an excess return over 12 months of $0.65 \%$ which is $2 \%$ worse than the $2.47 \%$ achieved by growth losers. The total effect being that style rotation using our forecasting models adds an additional $4 \%$ to the return that could be realised by building a long/short portfolio based on the value winners and the growth losers without any style rotation (see the bottom of panel 4.a).

Focusing on Panel $4 \mathrm{~b}$, the excess returns are documented when style rotation is applied to the (value and growth) loser portfolios. We find here that rotation right outperforms the value loser portfolio by about $2 \%$ while the rotation wrong portfolio underperforms the growth loser portfolio by about $3 \%$. The total impact being that style rotation, using our forecasting models, adds an additional $5 \%$ to the return that could be realised by building a long/short portfolio based on the value winners and the growth losers.

Perhaps it is most insightful to compare the findings reported in Table 3 with those reported in Table 4. From Table 3 we see that a long/short value/growth portfolio 
realised $7.53 \%$ over a 12 -month holding period and that this could be enhanced by slightly in excess of $7 \%$ by introducing style rotation. When we introduce the enhancement of value and growth using price momentum, we see that a spread of the returns between the rotation right on the winner portfolio and the rotation wrong on the loser portfolios of $28.40 \%$ (compared to a $14.64 \%$ without the sentiment enhancement). This return of $28.40 \%$ is composed of the value premium of $7.53 \%$, the increment due to the momentum enhancement of $15.83 \%$ and that due to style rotation of $5.04 \%$. It is particularly interesting to notice that the added value of $5.04 \%$ attributable to the style rotation is $2 \%$ less than that it generated in the absence of a momentum enhancement (7.11\%). As such the momentum enhancement is capturing some (around 2\%) of the added value that otherwise would be captured by the style rotation model. All of the above discussion has concentrated on our findings with a 12-month holding period, and an analysis of the returned reported in Table 4 indicates the added value attributable to style rotation is $2.59 \%$ ( $10.77 \%$ annualised) over a three-month holding period, $2.80 \%$ (5.68\% annualised) over a six-month holding period and $-1.31 \%(-0.66 \%$ annualised) over a 24-month holding period. These numbers indicate that style rotation works best in the months immediately after the signal is generated, and loses all of its ability to add value when one gets far beyond a 12-month holding period (again not surprising given that the model is based upon a 12-month forecasting horizon).

In summary, the results illustrated in the two panels of Table 4 propose a very interesting picture, where the style rotation indicator performs well in determining when to invest in the value portfolio and when to invest in the growth portfolio, with enhancements, in most instances, over and above those achieved with market sentiment for value and growth portfolios. This result highlights the possibility that the right (wrong) switches between the two style classes, as signalled by the macroeconomic factors, not only took advantage (disadvantage) from disinvesting (investing) in the under- (out-) performing style portfolio mostly at the right time, but also do so when a change in the market expectations set in. The consequence is a monotonic increase in the excess returns when moving from the wrong rotation to the right rotation passing through the enhanced value and enhanced growth portfolio. The main implication of these findings is for the switching regime between enhanced value and enhanced growth portfolios. Indeed, the results highlight the linkage of the life cycle of a stock to a change not only in the market sentiment but also in the intertemporal sensitivities of value and growth stocks to the phase where they are currently placed along the business cycle.

\section{Section 4.4: Further Improvement from Financial Health Indicator}

Bird and Casavecchia (2007) used 24 financial statement items to estimate a FH score for each company based on the forecasted probability that the company would experience an increase in its earnings per share during the current financial period (probit-health). This score exhibits an ability to identify the better performing value and growth stocks and to provide a further enhancement when used in combination with the price momentum indicator discussed in the previous sub-section.

We first replicate their results but using monthly rather than annual rebalancing, and then proceed to illustrate the contribution of style rotation when used in conjunction with the stock selection signals provided by market sentiment and $\mathrm{FH}$ indicators. We document our results in Table 5 in relation to those stocks with strong and weak market 
sentiment and a high and low probability of a future positive earnings release (top and bottom $1 / 3$ by momentum and FH or, respectively, "good" and "bad" stocks).

In Panel 5.a, we report our findings for good value and growth portfolios. Over a 12month holding period, rotation right adds slightly in excess of $2 \%$ in performance over the good value portfolio while rotation wrong underperforms good growth by almost $3 \%$. The overall result is that style rotation can significantly improve either a long-only strategy or a long/short strategy where the investment universe is composed of good value and growth stocks. Focusing on the other holding periods, style rotation seems to offer minimum improvements in performance over three months, significant incremental performance enhancement over six months (and 12 momths) but all the added value disappear by the time a holding period of 24 months is reached.

The ability of the style rotation to enhance portfolios composed of bad value and bad growth stocks is reported, instead, in Panel 5b. On the positive side, over a 12-month holding period, rotation right outperforms the bad value portfolio by almost $2.6 \%$ (which is slightly greater than the enhancement achieved by style rotation when applied to the good portfolio as reported in Table 5a) which is not necessarily a good outcome as it would detract from the contribution that the bad value and growth portfolios would make to a long/short strategy. A more germane finding is that rotation wrong realises about the same return as bad growth over both three-month and six-month holding periods but for longer holding periods rotation wrong outperforms bad growth. This is a bad outcome to the extent that it establishes that the style rotation signal from our model provides little in the way of enhancement to the performance of a long/short strategy beyond that which can be achieved by the application of the sentiment and $\mathrm{FH}$ indicators.

In Table 6 we present a decomposition of the long/short strategy drawing from the information contained in Tables 3, 4, and 5 and assuming a 12-month holding period. We have already stated that pure long/short value/growth strategy with no enhancements outperforms by $7.53 \%$, and that the introduction of the market sentiment increases this outperformance by a further $15.83 \%$. We saw in Table 5 that with the introduction of $\mathrm{FH}$, a long/short value/growth strategy (consisting of going long of good value and short of bad growth) with no style rotation will achieve a return of $29.68 \%$ (i.e. $17.73 \%+13.95 \%$ ) resulting in an incremental contribution of $\mathrm{FH}$ of $6.32 \%$ (i.e. $29.68 \%-[7.53 \%+15.83 \%])$. Finally, we have the contribution to total return from style rotation which is now reduced to $0.76 \%$ (i.e. $17.96 \%+12.48 \%-29.68 \%$ ) when used in concert with the other two enhancements. We asserted that the net contribution of style rotation to total performance was $7.11 \%$ in the absence of any enhancements to value and growth and that this reduced to $5.04 \%$ with the introduction of market sentiment. If we introduce $\mathrm{FH}$, this added value of $5.04 \%$ is furtherly reduced to $0.76 \%$.

We conclude the discussion of the findings by identifying some insights relating to the holding periods for the various strategies. Our results confirm findings from previous studies that the value premium increases as one extends the holding period out at least as long as 24 months, or longer. However, they also highlights that the three enhancements that we have introduced reduces the optimal holding period to something more like six months. This phenomenon is likely generated by the introduction of the sentiment indicator, which contributes to performance by delaying the entry to stocks whose own mean reversion in performance is several months ahead (i.e. the value trap). The usefulness of the sentiment indicator dramatically erodes beyond a six-month holding period. The contribution of the FH indicator is fairly constant for holding 
periods up to 12-months but rapidly erodes over longer periods. Again this is not surprising as our FH indicator is based upon forecasting earnings over the next 12 months and so loses its relevance over longer holding periods. Finally we contribution of style rotations peaks around six months and then rapidly declines. Two factors contributing to this decline are that: (i) we are forecasting the value premium over the next 12 months, and (ii) it would seem that particularly for bad value and bad growth portfolios the insights provided by our style rotation forecasts are already being captured by the previous two indicators (namely, sentiment and FH).

\section{Conclusions}

In this paper, we demonstrated that during the period 1993-2004, a number of macroeconomic and market factors were able, on a monthly basis, to predict the direction of the value premium over the next 12 months. The relationship between the business cycle and the value-growth spread adds another dimension to the value and momentum anomalies, given the size and robustness of the returns over different holding periods. The profitability generated by a rotation model between value and growth styles produced positive and significant excess returns, suggesting the possibility that the price adjustment of these stocks is a dynamic phenomenon not only across the market sentiment dimension, as already documented in the academic and professional literature, but also across the business cycle. These findings propose the existence, at least in the short run, of a real and quantitatively important macroeconomic dimension of the returns of value and growth stocks. The outperformance of the strategy to rotate between portfolios, constructed on either single valuation metrics or their enhancement by market sentiment and a company's financial strength, is consistent, monotonic, significant, and expected in its direction. This highlights the proposition that the macroeconomic factors capture a cross-sectional variation that is not typically impounded in the enhancement of value and growth portfolios when both sentiment and financial health indicators are applied. A conclusion that is supported by considering that: (i) the rotation model is developed solely to forecast the value premium, and (ii) in spite of this, the majority of the switches help to enhance the composite portfolios even after being timed by market sentiment and/or screened by the fundamental health of the companies (though it fails to do so in the case of those stocks with poor performance and fundamentals).

We also separated the contributions exerted by the two dimensions of the forecasting ability of the rotation model and the timing leverage of the portfolio construction. We emphasised the crucial importance of examining the relative impact of these two factors on the efficacy of a regression model developed to forecast switches between different asset classes. Even though the style rotation strategy returned a very high percentage of forecasting ability, we established that this result is partially attributable to the specific time series of the value premium used as the dependent variable. Nevertheless we also argued that for a style rotation strategy to be successful, it does not need to overcome a prohibitive forecasting threshold when attempting to outperform a naïve value or growth portfolio, ceteris paribus.

In general, our results propose a framework where the style rotation permits an investor to link the earnings and momentum life cycle of a stock, as proposed by Lee and Swaminathan (2000), to the macroeconomic intertemporal sensitivities of high and low sales-to-price portfolios. Although the sample covered in this study is between 1993 
and 2004 and does not really cover enough "economic business cycle", these results could provide some support also for the anomaly literature on European stocks, in particular if consideration is given to the fact that the (extent of) evidence cannot be completely explained by transaction costs, considering the large diffusion of the styleoriented ETF's in the last years, and the declining trend in the execution costs in most European markets, as a result of the competition between trading venues becoming fierce.

\section{Acknowledgments}

We have benefited from the comments of Anthony Hall, Steve Satchell, Geert Rouwenhorst, Brian Gendreau, David O’Toole, Nicola Bruti-Liberati, Nahid Rahman, Zhao Huainan, and the seminar participants at the European Financial Management Association, Austria, Financial Management Association, Florida, Imperial College London, and University of Technology, Sydney. We are also grateful to GMO London for kindly providing the dataset on the European sample.

\section{References}

Arshanapalli, B.T., Switzer,L.N., and Panju, K. (2007) Equity style timing: a multi-style rotation model for the Russell large-cap and small-cap growth and value style indexes, Journal of Asset Management, 8, pp. 9-23.

Asness, C.S. (1997) The interaction of value and momentum strategies, Financial Analysts Journal, 53, pp. 29-36.

Bartlett, M.S. (1937) Properties of sufficiency and statistical tests, Proceedings of the Royal Statistical Society, Series A, 160, pp. 268-282.

Biørn, E. (2001) How is generalized least squares related to within and between estimators in unbalanced panel data, University of Oslo, Unpublished Working Paper.

Bird, R. and Casavecchia, L. (2007) Sentiment and financial health indicators for value and growth stocks: The European experience, European Journal of Finance, 13, pp. 769-793.

Box, G.E.P. and Jenkins, G.M. (1976) Time series analysis forecasting and control, Holden Day.

Campbell, J.Y. (1987) Stock returns and the term structure, Journal of Financial Economics, 18, pp. 373-400.

Campbell, J.Y. and Shiller, R.J. (1988) Stock prices, earnings and expected dividends, Journal of Finance, 43, pp. 661-676.

Case, D.W. and Cusimano, S. (1995) Historical tendencies of equity style returns and the prospects for tactical style allocation, In R. Klein and J. Lederman, eds., Equity StyleManagement, Burr Ridge, IL: Irwin, 1995.

Chan, L.K.C, Karceski, J. and Lakonishok, J. (2000) New Paradigm or Some Old Hype in Equity Investing? Financial Analyst Journal, July/August.

Conrad, J. \& Kaul, G. (1993). Long-term market overreaction or biases in computes returns Journal of Finance. 48. 39-63.

Elton, E.J., Gruber, M.J., and Blake, C.R. (1995) Fundamental economic variables, expected returns, and bond fund performance, Journal of Finance, 50, pp. 1229-1256.

Fama, E.F. and Gibbons, K.R. (1984) A comparison of inflation forecasts, Journal of Monetary Economics, 13, pp. 327 - 348.

Fama, E.F. and French, K.R. (1988) Dividend yield and expected stock returns. Journal of Financial Economics, 22, pp. 3-25.

Fama, E.F. and French, K.R. (1989) Business conditions and expected returns on stocks and bonds, Journal of Financial Economics, 25, pp. 23-49. 
Fama, E.F. and French, K.R. (1993) Common risk factors in the returns on stocks and bonds. Journal of Financial Economics, 33, pp. 3-56.

Fama, E.F. and French, K.R. (1995) Size and book-to-market factors in earnings and returns, Journal of Finance, 50, pp. 131-155.

Fama, E.F. and French, K.R. (1996) Multifactor explanations of asset pricing anomalies, Journal of Finance, 51, pp. 55-87.

Ferson, W.E. and Harvey, C.R. (1991) The variation of economic risk premiums, Journal of Political Economy, 99, pp. 385-415.

Ferson, W.E. and Harvey, C.R. (1999) Conditioning variables and the cross section of stock returns, Journal of Finance, 54, pp. 1325-1360.

Hamilton, J.D. (1994) Time series analysis, Princeton: Princeton University Press, N.J.

Holland, P.W. and Welsch, R.E. (1977) Robustness regression using iteratively reweighted least-squares, Communications in Statistics - Theory and Methods, 6, pp. 813-827.

Jeffrey, R.H. (1984). The folly of stock market timing, Harvard Business Review, 62, pp. 102110.

Keim, D.B. and Stambaugh, R.F. (1986) Predicting returns in the bond and stock markets. Journal of Financial Economics, 17, pp. 357-390.

Lee, C.M.C. and Swaminathan, B. (2000) Price momentum and trading volume, Journal of Finance, 55, pp. 2017-2069.

Maddala, G.S., (2003) Introduction to econometrics, Wiley, London.

Newey, W.K., West, K.D. (1987) A simple, positive semi-definite, heteroskedasticity and autocorrelation consistent covariance matrix, Econometrica, 55, pp. 703-708.

Oertmann, P. (1999) Why do value stocks earn higher returns than growth stocks, and viceversa? University of St. Gallen, Unpublished Working Paper.

White, H. (1980) A heteroskedasticity-consistent covariance matrix estimator and a direct test for heteroskedasticity, Econometrica, 48, pp. 817-838. 


\section{Appendix A: Conditional economy-wide instrumental model}

In this section we applied the conditional regression model proposed by Ferson and Harvey (1999), in order to quantify the predictive ability of macroeconomic variables. If the sensitivities of value (high sales-to-price) and growth (low sales-to-price) portfolios to the changing "business cycles" are constant, a style rotation model conditional on the lagged economy-wide variables utilised in the current paper would prove superfluous. Therefore, our aim is to analyse the extent of the common dynamics seized by our lagged macroeconomic instruments (outlined in section 2) and not represented by the Fama and French three factor-mimicking portfolios (MARKET, SMB and HML). Our expectation, consistent with the result obtained by Ferson and Harvey for US, is that across the fifteen European markets considered in this paper, the use of lagged economic instruments to seize time-varying conditional expectations would reveal information that is not impounded in the popular three-factor model of Fama and French $(1993 ; 1995 ; 1996)$ and the four-factor model of Elton, Gruber, and Blake (1995).

The conditional regression model can be summarised as follows:

$$
R_{i, t+1}=\left(\alpha_{o, i}+\alpha_{1, i}^{\prime} Z_{t}\right)+\left(b_{0, i}+b_{1, i}^{\prime} Z_{t}\right) R_{p, t+1}+\varepsilon_{i, t+1}
$$

where the term $R_{i, t+1}$ represents the return, net of the 3-month Treasury Bill returns, of the portfolios of stocks separated by size (market capitalisation) and book-to-market. $R_{p, t+1}$ constitutes the excess return of factor-mimicking portfolios (MARKET, SMB and HML). The HML represents portfolios long (short) of high (low) book-to-market stocks whereas SMB is a portfolio long (short) in stocks with small (large) market capitalisation. The portfolios are formed by ranking firms in August of each year $t$ on market capitalisation and book-to-market variables. Monthly value-weighted returns are then calculated from September of year $t$ (to be sure that the book value is known) to August of year $t+1$

If the lagged macroeconomic instruments $\left(Z_{t}\right)$ and the interaction terms between the factor-mimicking portfolios and the lagged instruments $\left(Z_{t} R_{p, t+1}\right)$ cannot be excluded from the regression without reducing its explanatory power, a conditional version (in the $\alpha$ 's and the $\beta$ 's) of an asset pricing model may be better than unconditional models in explaining the changing required returns.

In table A.1, we document the R-squares of the regressions for conditional (column [2] and [4]) and unconditional (column [1] and [3]) betas controlling for constant or time-varying alphas. The model is estimated with a 5 year rolling window. The table also documents the right-tailed p-values of the F-test for the hypothesis that the lagged macroeconomic variables may be excluded from the regressions. In the case of timevarying alphas, in all but 5 instances, the F-test strongly rejects the hypothesis of unconditional macroeconomic sensitivities of the dependent portfolios whereas in the case of constant alphas, in all but 6 cases we accept the alternative of conditional betas. 
Table A.1: Test of conditional versus unconditional regression model.

\begin{tabular}{|c|c|c|c|c|c|c|}
\hline \multirow[b]{2}{*}{ Portfolio } & \multicolumn{3}{|c|}{$\mathrm{R}^{2}$ Time- $\mathrm{V}$ arying Alphas } & \multicolumn{3}{|c|}{$\mathrm{R}^{2}$ Constant Alphas } \\
\hline & $\begin{array}{c}\text { Constant } \beta \\
{[1]}\end{array}$ & $\begin{array}{c}\text { Time-V arying } \beta \\
{[2]} \\
\end{array}$ & $\begin{array}{c}\text { F-Test } \\
\text { p-values }\end{array}$ & $\begin{array}{c}\text { Constant } \beta \\
{[3]}\end{array}$ & $\begin{array}{c}\text { Time- } \mathrm{V} \text { arying } \beta \\
{[4]}\end{array}$ & $\begin{array}{l}\text { F-T est } \\
\text { p-values }\end{array}$ \\
\hline S1/B1 & 0.654 & 0.682 & 0.07 & 0.462 & 0.508 & 0.09 \\
\hline $\mathrm{S} 1 / \mathrm{B} 2$ & 0.470 & 0.544 & 0.00 & 0.293 & 0.443 & 0.00 \\
\hline S1/B3 & 0.701 & 0.742 & 0.00 & 0.641 & 0.690 & 0.00 \\
\hline S1/B4 & 0.612 & 0.669 & 0.13 & 0.513 & 0.553 & 0.22 \\
\hline $\mathrm{S} 1 / \mathrm{B} 5$ & 0.731 & 0.759 & 0.02 & 0.646 & 0.709 & 0.00 \\
\hline $\mathrm{S} 2 / \mathrm{B} 1$ & 0.786 & 0.820 & 0.12 & 0.734 & 0.759 & 0.25 \\
\hline $\mathrm{S} 2 / \mathrm{B} 2$ & 0.840 & 0.850 & 0.03 & 0.816 & 0.819 & 0.05 \\
\hline $\mathrm{S} 2 / \mathrm{B} 3$ & 0.862 & 0.879 & 0.00 & 0.839 & 0.857 & 0.00 \\
\hline $\mathrm{S} 2 / \mathrm{B} 4$ & 0.855 & 0.881 & 0.00 & 0.797 & 0.834 & 0.00 \\
\hline $\mathrm{S} 2 / \mathrm{B} 5$ & 0.746 & 0.757 & 0.18 & 0.667 & 0.695 & 0.15 \\
\hline S3/B1 & 0.862 & 0.898 & 0.00 & 0.808 & 0.843 & 0.00 \\
\hline $\mathrm{S} 3 / \mathrm{B} 2$ & 0.882 & 0.904 & 0.01 & 0.875 & 0.894 & 0.00 \\
\hline $\mathrm{S} 3 / \mathrm{B} 3$ & 0.814 & 0.835 & 0.00 & 0.782 & 0.799 & 0.00 \\
\hline $\mathrm{S} 3 / \mathrm{B} 4$ & 0.803 & 0.820 & 0.00 & 0.783 & 0.794 & 0.00 \\
\hline $\mathrm{S} 3 / \mathrm{B} 5$ & 0.811 & 0.853 & 0.00 & 0.781 & 0.814 & 0.00 \\
\hline $\mathrm{S} 4 / \mathrm{B} 1$ & 0.889 & 0.919 & 0.01 & 0.851 & 0.873 & 0.04 \\
\hline $\mathrm{S} 4 / \mathrm{B} 2$ & 0.832 & 0.876 & 0.00 & 0.738 & 0.859 & 0.01 \\
\hline $\mathrm{S} 4 / \mathrm{B} 3$ & 0.814 & 0.832 & 0.01 & 0.776 & 0.803 & 0.00 \\
\hline $\mathrm{S} 4 / \mathrm{B} 4$ & 0.847 & 0.867 & 0.00 & 0.802 & 0.831 & 0.00 \\
\hline $\mathrm{S} 4 / \mathrm{B} 5$ & 0.757 & 0.814 & 0.00 & 0.720 & 0.748 & 0.02 \\
\hline S5/B1 & 0.914 & 0.920 & 0.03 & 0.898 & 0.902 & 0.21 \\
\hline S5/B2 & 0.916 & 0.930 & 0.00 & 0.899 & 0.911 & 0.01 \\
\hline S5/B3 & 0.940 & 0.952 & 0.00 & 0.931 & 0.941 & 0.00 \\
\hline S5/B4 & 0.889 & 0.903 & 0.00 & 0.863 & 0.875 & 0.01 \\
\hline S5/B 5 & 0.797 & 0.810 & 0.22 & 0.755 & 0.770 & 0.25 \\
\hline
\end{tabular}

In this table we document the adjusted R-squares of four different unconditional and conditional (to the lagged macroeconomic instruments) regressions. The dependent variables are 25 portfolios separated according to their size (market capitalisation) and book-to-market (BE/ME) characteristics. The independent variables are the unconditional and conditional alphas and the unconditional and conditional betas. The R-squares in column [1] and [2] are those of a regression with time-varying (conditional) alpha when the beta are either constant (Market, SMB, HML) or time-varying (we allow for the interaction between the three factor-mimicking portfolios and the lagged macroeconomic variables to enter the regression). Column [3] and [4] are related to regressions with unconditional alphas for the two cases of constant betas (Market, SMB, HML) and time-varying betas (interaction terms are included). The sample period is from January 1990 and May 2004. We also calculated the F-test of the hypothesis of conditional betas for the case where alphas are either time-varying (columns [1] and [2]) or constant (column [3] and [4]). 
Table 1: Descriptive statistics and correlation matrix of the financial and macroeconomic factors Panel A

\begin{tabular}{|c|c|c|c|c|c|c|}
\hline & Value Premium & $\begin{array}{c}\text { Unexpected } \\
\text { Inflation }\end{array}$ & Baa-Aaa & $\begin{array}{c}\text { Euro Div. } \\
\text { Yield }\end{array}$ & YTM & Real T.B. \\
\hline Mean & $0.0 \%$ & $0.0 \%$ & $0.8 \%$ & $2.6 \%$ & $0.8 \%$ & $5.3 \%$ \\
\hline Median & $0.0 \%$ & $0.0 \%$ & $0.7 \%$ & $2.6 \%$ & $0.9 \%$ & $5.5 \%$ \\
\hline Standard Deviation & $0.5 \%$ & $0.0 \%$ & $0.2 \%$ & $0.5 \%$ & $1.0 \%$ & $1.1 \%$ \\
\hline Minimum & $-1.8 \%$ & $-0.1 \%$ & $0.6 \%$ & $1.6 \%$ & $-1.4 \%$ & $3.3 \%$ \\
\hline Maximum & $2.6 \%$ & $0.2 \%$ & $1.4 \%$ & $3.6 \%$ & $2.9 \%$ & $7.4 \%$ \\
\hline \multicolumn{7}{|l|}{ Pane1 B } \\
\hline & Value Premium & $\begin{array}{c}\text { Unexpected } \\
\text { Inflation }\end{array}$ & $\mathrm{Baa}-\mathrm{Aaa}$ & $\begin{array}{c}\text { Euro Div. } \\
\text { Yield }\end{array}$ & YTM & Real T.B. \\
\hline Value Premium & 1 & -0.016 & -0.012 & -0.033 & 0.057 & 0.045 \\
\hline Unexp. Inflation & & 1 & 0.006 & 0.081 & 0.120 & -0.037 \\
\hline Baa-Aaa & & & 1 & 0.059 & -0.045 & 0.229 \\
\hline Euro Div. Yield & & & & 1 & 0.206 & 0.223 \\
\hline YTM & & & & & 1 & -0.336 \\
\hline Real T.B. & & & & & & 1 \\
\hline
\end{tabular}

In the table, we document the main statistics of the macroeconomic variables (in panel A) as well as the median coefficients of correlation obtained with a bootstrap over 10,000 draws (in panel B). The values are related to the entire holding period between 1990 and 2004. The variables considered include the monthly time series of the value premium; the Fama-Gibbons (1984) monthly unexpected inflation; the monthly spread between Moody's Baa and Aaa yields (Baa-Aaa); the monthly series of the dividend yields (Euro Div. Yield); the monthly spread between the 10-year and the three-month Treasury bill (YTM); the monthly difference between the 3-month Treasury Bills returns and the monthly rate of inflation (real T.B.). 
Table 2: In-sample univariate and multivariate estimations of the factor sensitivities

\begin{tabular}{|c|c|c|c|c|}
\hline & \multirow{2}{*}{$\frac{\text { Multivariate }}{\text { Estimates }}$} & \multicolumn{3}{|c|}{ Univariate } \\
\hline & & Alpha & Beta & MSE \\
\hline \multirow[t]{2}{*}{ Vpremium 12m(t-1) } & 0.345 & -0.018 & 0.770 & \\
\hline & {$[1.892]$} & {$[-19.829]$} & {$[2.282]$} & 0.0000 \\
\hline \multirow[t]{2}{*}{ Unexpected Inflation } & -0.427 & -0.018 & -0.752 & \\
\hline & {$[-1.878]$} & {$[-19.411$} & {$[-0.727]$} & 0.0000 \\
\hline \multirow[t]{2}{*}{ Baa-Aaa } & -0.285 & -0.019 & -0.045 & \\
\hline & {$[-0.857]$} & {$[-16.482]$} & {$[-1.329]$} & 0.0000 \\
\hline \multirow[t]{2}{*}{ Euro DivYield } & 0.347 & -0.008 & 0.496 & \\
\hline & {$[1.924]$} & {$[-8.891]$} & {$[4.555]$} & 0.0000 \\
\hline \multirow[t]{2}{*}{ YTMI } & 0.090 & -0.013 & 0.083 & \\
\hline & [2.166] & {$[-7.306]$} & {$[2.079]$} & 0.0000 \\
\hline \multirow[t]{2}{*}{ Real TB } & -0.052 & -0.018 & -0.128 & \\
\hline & {$[-1.881]$} & {$[-15.077]$} & {$[-2.514]$} & 0.0000 \\
\hline \multirow[t]{2}{*}{ Alpha (multivar) } & -0.002 & & & \\
\hline & {$[-5.476]$} & & & \\
\hline MSE (multivar) & 0.0000 & & & \\
\hline
\end{tabular}

In this table, we document the results obtained from multivariate and univariate regression coefficients. The regression model is a time-weighted least square (WLS-exponential) where the observations are time weighted in the in-sample period in order to down-weight obsolete macroeconomic information more severely. The regression is estimated over a 36-month window in each month of the sample period. The entire sample period ranges between 1990 and 2004. We document the t-statistics (in square brackets) and the mean square error (MSE) of the estimations for either the univariate or the multivariate case. The variables considered include the monthly time series of the value premium; the Fama-Gibbons (1984) monthly unexpected inflation; the monthly spread between Moody's Baa and Aaa yields (Baa-Aaa); the monthly series of the dividend yields (Euro Div. Yield); the monthly spread between the 10-year and the three-month Treasury bill (YTM); the monthly difference between the 3-month Treasury Bills returns and the monthly rate of inflation (real T.B.). 
Table 3: Cumulated excess returns to a style rotation strategy: single criterion

\begin{tabular}{lcccc}
\hline Holding period & 3 months & 6 months & 12 months & 24 months \\
\hline Rotation Right & $2.46 \%$ & $4.87 \%$ & $9.53 \%$ & $11.28 \%$ \\
& {$[0.043]$} & {$[0.167]$} & {$[0.013]$} & {$[0.029]$} \\
Value (top 1/4) & $0.87 \%$ & $2.07 \%$ & $5.56 \%$ & $13.54 \%$ \\
& {$[0.119]$} & {$[0.120]$} & {$[0.002]$} & {$[0.016]$} \\
Growth & $-0.35 \%$ & $-0.91 \%$ & $-1.97 \%$ & $-8.42 \%$ \\
& {$[0.148]$} & {$[0.030]$} & {$[0.038]$} & {$[0.023]$} \\
Rotation Wrong & $-1.77 \%$ & $-3.34 \%$ & $-5.11 \%$ & $-6.25 \%$ \\
& {$[0.095]$} & {$[0.037]$} & {$[0.119]$} & {$[0.106]$} \\
Right - Wrong & $4.23 \% *$ & $8.21 \% * *$ & $14.64 \% \%^{* * *}$ & $17.53 \% \%^{* * * *}$ \\
Value - Growth & $1.22 \%$ & $2.99 \%$ & $7.53 \% *$ & $21.96 \%$ \\
\hline
\end{tabular}

[*] $90 \%$ significance level; [**) $95 \%$ significance level; [(***) $99 \%$ significance level

In each month, from 1993 to 2004 (out-of-sample period), all available stocks are sorted based on their Sales-to-Price, with those in the top $1 / 4$ being assigned to the value portfolio and those in the bottom $1 / 4$ being assigned to the growth portfolio. We also report the portfolios generated by macroeconomic rotation, where rotation right (wrong) refers to a portfolio constructed by switching between value and growth stocks according (opposite) to the signals returned by the regression model. The accumulated excess returns are measured over different holding periods from three to 24 months (they are not annualized). The average of the accumulated excess returns is documented as well as the Newey-West (1987) $p$-values, corrected for the autocorrelation and heteroskedasticity, to test the significance of the excess returns. We also document the significance levels of the statistical test of the differences between the sample means by using the Bonferroni corrections. 
Table 4: Cumulated excess returns to a style rotation strategy: value and growth enhanced by market sentiment

\begin{tabular}{lcccc}
\multicolumn{5}{l}{ Panle 4.a: Portfolios with strong sentiment (top 1/3) } \\
\hline Holding period & 3 months & 6 months & 12 months & 24 months \\
\hline Rotation Right & $4.01 \%$ & $7.71 \%$ & $13.83 \%$ & $10.91 \%$ \\
& {$[0.115]$} & {$[0.119]$} & {$[0.118]$} & {$[0.003]$} \\
Value (top 1/4) & $3.75 \%$ & $7.61 \%$ & $11.87 \%$ & $18.38 \%$ \\
& {$[0.160]$} & {$[0.026]$} & {$[0.106]$} & {$[0.142]$} \\
Growth (bottom 1/4) & $2.87 \%$ & $4.00 \%$ & $2.47 \%$ & $-6.55 \%$ \\
& {$[0.012]$} & {$[0.031]$} & {$[0.144]$} & {$[0.035]$} \\
Rotation Wrong & $2.78 \%$ & $2.82 \%$ & $0.65 \%$ & $-7.74 \%$ \\
& {$[0.147]$} & {$[0.006]$} & {$[0.122]$} & {$[0.004]$} \\
& $1.23 \%{ }^{*}$ & $4.89 \%{ }^{* *}$ & $13.18 \% * * *$ & $18.65 \% * * *$ \\
Right - Wrong & $0.88 \%{ }^{*}$ & $3.62 \% \%^{* * *}$ & $9.40 \%{ }^{* * *}$ & $24.92 \%$ \\
\hline Value - Growth &
\end{tabular}

(*) $90 \%$ significance level; [**) $95 \%$ significance level; [ [***) $99 \%$ significance level

Panle 4.b: Portfolios with poor sentiment (bottom 1/3)

\begin{tabular}{lcccc}
\hline Holding period & 3 months & 6 months & 12 months & 24 months \\
\hline Rotation Right & $-0.59 \%$ & $-1.19 \%$ & $1.59 \%$ & $8.85 \%$ \\
& {$[0.085]$} & {$[0.120]$} & {$[0.012]$} & {$[0.007]$} \\
Value (top 1/4) & $-1.40 \%$ & $-1.43 \%$ & $-0.35 \%$ & $6.54 \%$ \\
& {$[0.136]$} & {$[0.102]$} & {$[0.104]$} & {$[0.039]$} \\
Growth (bottom 1/4) & $-3.62 \%$ & $-7.72 \%$ & $-11.49 \%$ & $-13.89 \%$ \\
& {$[0.033]$} & {$[0.017]$} & {$[0.019]$} & {$[0.073]$} \\
Rotation Wrong & $-5.95 \%$ & $-10.42 \%$ & $-14.57 \%$ & $-20.05 \%$ \\
& {$[0.081]$} & {$[0.053]$} & {$[0.022]$} & {$[0.092]$} \\
Right - Wrong & $5.36 \% \%^{* * * *}$ & $9.23 \% \%^{* * *}$ & $16.17 \%^{* *}$ & $28.90 \% \%^{* * * *}$ \\
Value - Growth & $2.21 \% \%^{* * *}$ & $6.29 \%$ & $11.14 \%^{*}$ & $20.43 \%$ \\
\hline
\end{tabular}

$\left[{ }^{*}\right.$ ] $90 \%$ significance level; [**) $95 \%$ significance level; [***) $99 \%$ significance level

In each month, from 1993 to 2004 (out-of-sample period), all available stocks are sorted based on their sales-to-price, with those in the top $1 / 4$ being designated as value stocks and those in the bottom $1 / 4$ being designated as growth stocks. The same stocks area also sorted by their price momentum over the previous six months, with the top (bottom) $1 / 3$ being the Winner (Loser) portfolios. Value/growth and rotation right/wrong portfolios are then combined with the top (Panel 4.a) and bottom (Panel 4.b) $1 / 3$ of sentiment portfolios. The style timing model is used to forecast the value premium which is used to determine the right (wrong) style rotation each month and this signal is then used in combination with winner (loser) value and growth portfolios to form rotation right and rotation wrong portfolios whose performance are also reported in Panel 4a (Panel 4b). The accumulated excess returns are measured over different holding periods from three to 24 months (they are not annualized). The average of the accumulated excess returns is documented as well as the Newey-West (1987) p-values, corrected for the autocorrelation and heteroskedasticity, to test the significance of the excess returns. We also document the significance levels of the statistical test of the differences between the sample means by using the Bonferroni corrections. 
Table 5: Cumulated excess returns to a style rotation strategy: value and growth enhanced by both momentum and financial health

\begin{tabular}{|c|c|c|c|c|}
\hline Holding period & 3 months & 6 months & 12 months & 24 months \\
\hline \multirow[t]{2}{*}{ Rotation Right } & $4.66 \%$ & $11.32 \%$ & $17.96 \%$ & $16.87 \%$ \\
\hline & {$[0.062]$} & [0.080] & [0.094] & [0.099] \\
\hline \multirow[t]{2}{*}{ Value $($ top $1 / 4)$} & $4.28 \%$ & $8.86 \%$ & $15.73 \%$ & $16.91 \%$ \\
\hline & [0.113] & {$[0.135]$} & {$[0.026]$} & {$[0.095]$} \\
\hline \multirow[t]{2}{*}{ Growth (bottom 1/4) } & $3.70 \%$ & $5.93 \%$ & $684 \%$ & $-2.30 \%$ \\
\hline & [0.049] & {$[0.060]$} & {$[0.015]$} & {$[0.043]$} \\
\hline \multirow[t]{2}{*}{ Rotation Wrong } & $3.68 \%$ & $5.37 \%$ & $4.01 \%$ & $-1.47 \%$ \\
\hline & {$[0.138]$} & {$[0.032]$} & {$[0.155]$} & {$[0.071]$} \\
\hline Right - Wrong & $0.98 \%^{\text {**** }}$ & $5.95 \% * *$ & $13.94 \%^{* * * *}$ & $18.34 \%^{* * *}$ \\
\hline Value - Growth & $0.58 \%{ }^{*}$ & $2.93 \%{ }^{* * *}$ & $8.89 \%^{* * *}$ & $19.21 \%^{*}$ \\
\hline \multicolumn{5}{|c|}{ 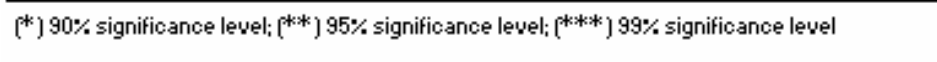 } \\
\hline \multicolumn{5}{|c|}{ Panle 5.b: Portfolios with poor sentiment and financial health (bot 1/3) } \\
\hline Holding period & 3 months & 6 months & 12 months 2 & 24 months \\
\hline \multirow[t]{2}{*}{ Rotation Right } & $-1.93 \%$ & $-0.99 \%$ & $0.88 \%$ & $6.65 \%$ \\
\hline & {$[0.013]$} & [0.119] & {$[0.073]$} & {$[0.162]$} \\
\hline \multirow[t]{2}{*}{ Value (top 1/4) } & $-2.28 \%$ & $-2.47 \%$ & $-1.71 \%$ & $7.90 \%$ \\
\hline & {$[0.002]$} & {$[0.026]$} & {$[0.092]$} & {$[0.005]$} \\
\hline \multirow[t]{2}{*}{ Growth (bottom 1/4) } & $-4.35 \%$ & $-9.20 \%$ & $-13.95 \%$ & $-12.03 \%$ \\
\hline & {$[0.148]$} & {$[0.031]$} & [0.099] & {$[0.095]$} \\
\hline \multirow[t]{2}{*}{ Rotation Wrong } & $-4.36 \%$ & $-9.46 \%$ & $-12.48 \%$ & $-8.39 \%$ \\
\hline & {$[0.119]$} & {$[0.006]$} & {$[0.095]$} & {$[0.023]$} \\
\hline Right - Wrong & $2.43 \% * *$ & $8.47 \% *$ & $13.37 \%$ & $15.04 \%$ \\
\hline Value - Growth & $2.08 \%{ }^{*}$ & $6.73 \%^{*}$ & $12.24 \%^{* * *}$ & $19.92 \%$ \\
\hline
\end{tabular}

[*] $90 \%$ significance level; [**) $95 \%$ significance level; [***) $99 \%$ significance level

In each month, from 1993 to 2004 (out-of-sample period), all available stocks are sorted based on their sales-to-price, with those in the top $1 / 4$ being designated as value stocks and those in the bottom $1 / 4$ being designated as growth stocks. The same stocks area also sorted by their price momentum and financial health with the top (bottom) $1 / 3$ of both indicators providing the basis for forming both good (and bad) value and growth portfolios whose performance is reported in Panel a (Panel b). The style timing model is used to forecast the value premium which is used to determine the right (wrong) style rotation each month and this signal is then used in combination with good (bad) value and growth portfolios to form rotation right and rotation wrong portfolios whose performance are also reported in Panel 5a (Panel 5b). The accumulated excess returns are measured for each of the portfolios over different holding periods from three to 24 months (they are not annualized). The average of the accumulated excess returns is documented as well as the Newey-West (1987) p-values, corrected for the autocorrelation and heteroskedasticity, to test the significance of the excess returns. We also document the significance levels of the statistical test of the differences between the sample means by using the Bonferroni corrections. 
Table 6: Decomposition of the excess returns on long/short portfolios enhanced with market sentiment, financial health and style rotation

\begin{tabular}{lccc}
\hline \multicolumn{4}{c}{ Decomposition of Excess Retums of Value and Growth Stocks (\%) } \\
\hline $\begin{array}{l}\text { Components of long/short } \\
\text { portfolio excess returns } \\
\text { attributable to: }\end{array}$ & $\begin{array}{c}\text { No Enhancement } \\
\text { Enhancement through } \\
\text { Market Sentiment }\end{array}$ & $\begin{array}{c}\text { Enhancement through } \\
\text { market sentiment \& } \\
\text { financial health } \\
{[3]}\end{array}$ \\
\hline Value premium [a] & 7.53 & {$[2]$} & 7.53 \\
Market sentiment [b] & --- & 7.53 & 15.83 \\
Financial health [c] & --- & 15.83 & 6.32 \\
Style Rotation [d] & 7.11 & --- & 0.76 \\
\hline Total & $\mathbf{1 4 . 6 4}$ & 5.04 & $\mathbf{3 0 . 4 4}$ \\
\hline
\end{tabular}

This table decomposes the 12-month excess returns on long/short value and growth portfolios enhanced by using market sentiment, financial heath and style rotation. This decomposition highlights the monthly contribution of each factor ([a]-[d]) across the three different steps of the analysis: [1] no portfolio enhancement (namely, value and growth portfolios alone), [2] style portfolios augmented by their market sentiment, and [3] style portfolios enhanced by both market sentiment and companies financial health along the earnings and momentum life cycles of each firm. 

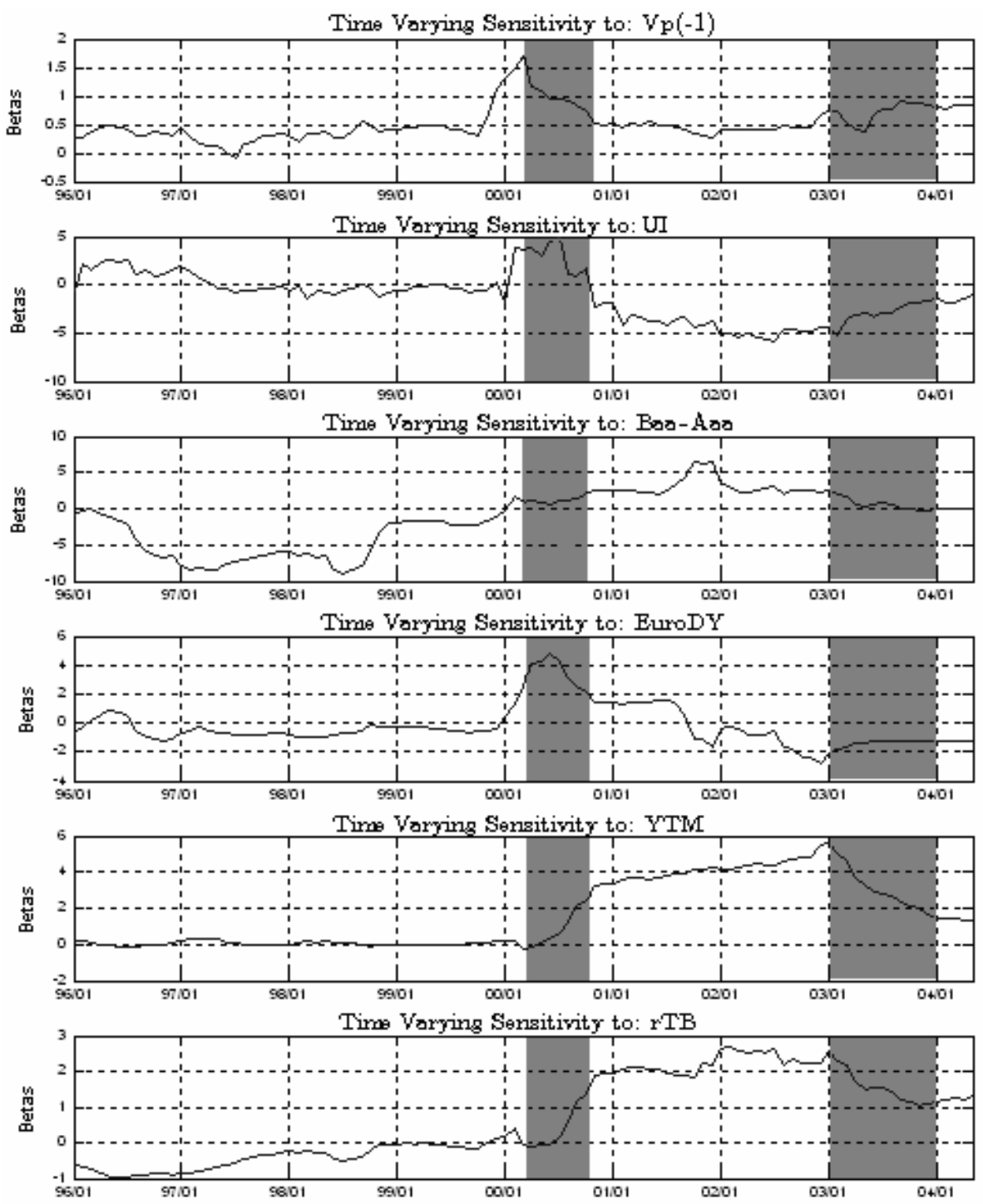

Figure 1: In this figure, we document the variation through time of the sensitivities of the value and growth portfolios to the instrumental variables utilised in our style rotation model. The variables include the lagged values of: "V $\mathbf{p}_{\mathbf{t}-1}$ ", the monthly time series of the value premium; the "UI", the Fama-Gibbons (1984) monthly unexpected inflation; the "Baa-Aaa", the monthly spread between Moody's Baa and Aaa yields; the "EuroDY", the monthly series of the dividend yields for our European sample; the "YTM", the monthly spread between the 10-year and the three-month Treasury bill; the "rTB", the monthly difference between the 3-month Treasury Bills returns and the monthly rate of inflation. The sample period ranges between January 1990 and May 2004. The regression coefficients are estimated iteratively each month over a 36-month window. We also highlighted the main changes in the trends of the coefficients in the grey areas (notice that the time interval March-November 2001 corresponds to the recession period for the US economy, as indicated by the NBER Business Cycles Dates Committee). 
Panel 2.a: Forecasting Ability and Timing Leverage: A Bootstrap Simulation

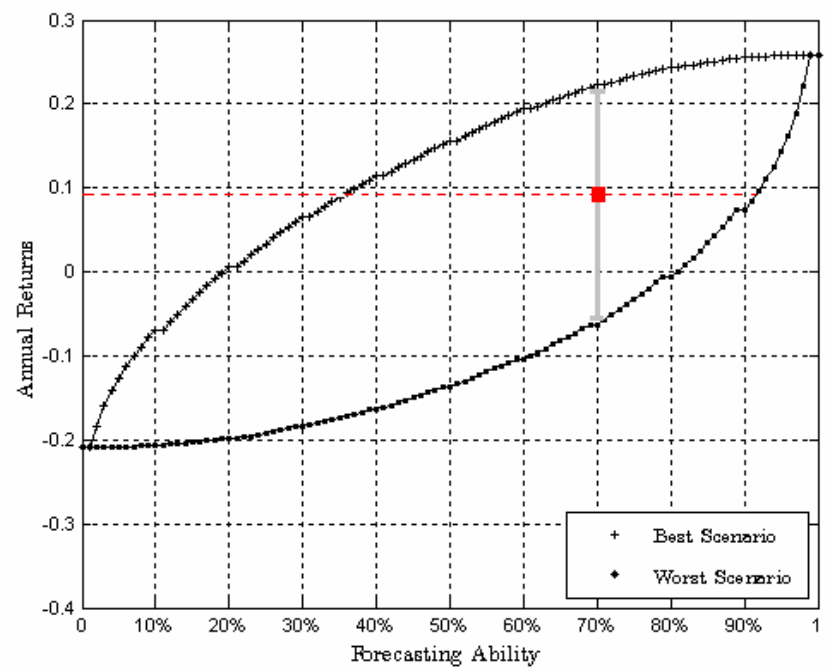

Panel 2.b: ECDFs for Different Style Rotation Abilities in the Best Scenario
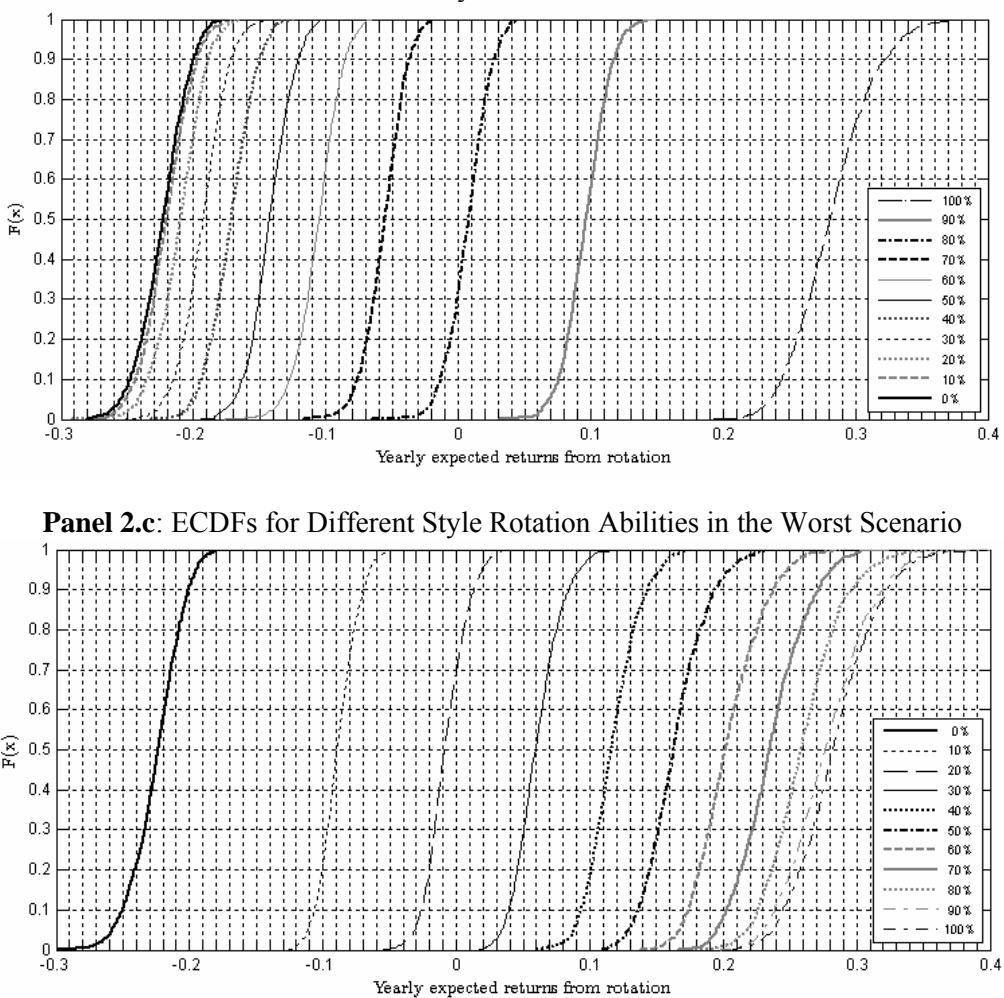

Figure 2: In this graph, we report in panel 2.a the region of potential returns generated by the style rotation in relation to two dimensions of: forecasting abilities and timing leverage. The best and worst scenarios for different forecasting abilities are the result of a bootstrap simulation with 10,000 draws from the time series of the value premium. In panel $2 . b$ and panel 2.c, we illustrate the distributions of 12 month excess returns generated by different forecasting abilities on the rotations between value and growth portfolios, respectively in the case of the extreme best (panel 2.b) and extreme worst (panel 2.c) scenarios. Indeed, for each (excess) return relative to each level of forecasting ability in panel 2.a, there is $\mathrm{a}(\mathrm{n})$ (empirical cumulated) distribution (ECDF) of (excess) returns generated by different combinations of months in which to rotate between value and growth styles. 


\section{Notes}

${ }^{i}$ The only difference with their analysis is that we construct and rebalance portfolios on a monthly, rather than yearly, basis.

ii The countries considered are: France, Italy, The Netherlands, Germany, Spain, United Kingdom, Belgium, Portugal, Ireland, Austria, Greece, Norway, Sweden, Denmark, and Finland.

iii Conrad and Kaul (1993) documented that much of the evidence on the long horizon mean reversion are generated by low-priced stocks, and that these stocks also exhibit a strong return reversal in January. Therefore, in order to avoid this problem, we follow the common practice of imposing cutoffs on minimum prices and number of analysts. However, the removal of these thresholds does not particularly affect the conclusions, as the only thing it does is to smooth the January effect in most of the European markets.

iv The construction of the financial health indicator is based instead on accounting data expressed in local currency. The final financial health score is a probability measure of the profitability, financial stability and operating efficiency of a company (see Bird and Casavecchia, 2007),

${ }^{\mathrm{v}}$ For a detailed description of the implementation of the back-forecasting procedure of Box and Jenkins, see Hamilton (1994).

${ }^{\mathrm{vi}}$ A further reason is related to the heavily unbalanced time series of the value premium over different in-sample periods, and the high skewness of the intra-style distributions. These characteristics can spuriously and automatically affect the constant term and, consequently, drive the high (low) probability of correct forecasts as a result of different proportions of 0's and 1's, rather than as a consequence of a real efficacy of the probabilistic model itself (see Maddala, 2003, p. 325). If the time series were strongly autocorrelated through time, thus, we would achieve a high probability of correct forecast irrespective of the fit of the model.

vii A Bartlett (1937) test of equality for variances between series decisively rejects the null hypothesis of equal variance of the residuals, providing strong evidence of the presence of groupwise heteroskedasticity.

viii We also applied an iterative reweighted least square (IRLS) where the vector of residuals from the previous iteration is used to weight the observation of the regression in order to reduce the effect of large residuals. The IRLS relies on an accurate and prefixed scale estimate for the definition of its weights. In this case, we used the Holland and Welsch (1977) tuning constant as auxiliary scale factor, which is equal to 2.985 times the median of absolute deviations (MAD). The results of the regressions do not seem to be particularly sensitive to the scale estimate used to weight the residuals in our in-sample period. Moreover, because the results of the two methods are very similar, for the further development of our style rotation model we decided to use and report only on the exponential time-weighting approach. The findings of the IRLS can be obtained from the authors on request.

${ }^{\text {ix }}$ In Appendix A of this paper we also performed a detailed analysis of the extent of the cross-sectional variation of the returns of value and growth portfolios conditional on the lagged economy-wide instruments. The results of the tests on the conditional versus unconditional regression models strongly reject the hypothesis that the lagged economic variables may be excluded from a model that tries to forecast the time-varying sensitivities of portfolios as separated according to their size and book-to-market characteristics.

${ }^{\mathrm{x}}$ The autocorrelation of the value premium dies out in 4 months, but is particularly significant in the first two. 